\title{
Analysis of Research Trends in Parents of Children with Autism Spectrum Disorder in Korea
}

\author{
Jeong-Hye Lee ${ }^{1}$, Soon-Gil Park², Mee-Ran Park \\ ${ }^{I}$ Supervisor, Gwangju Metropolitan Office of Education, Republic of Korea, lih019@ korea.kr \\ ${ }^{2}$ Professor, Dept. Elementary Special Education, Nambu University, Republic of Korea, \\ psoongil@nambu.ac.kr \\ ${ }^{3}$ Doctor's Course, Dept. Special Education, Nambu University, Republic of Korea, \\ nabi1338@hanmail.net \\ Corresponding author: Soon-Gil Park
}

\begin{abstract}
This study analyzed previous studies to suggest research directions for children with autistic disorders in Korea. In order to achieve this purpose, the general characteristics of parents of children with autistic disorders and research trends according to evidence-based practice were investigated. The literature on analysis related to parents of children with autistic disorder has a total of 24 studies, general characteristics (research target, Independent Variable, Dependent Variable, Research design) and evidence-based actual qualitative indicators were analyzed. Korean journal articles published between 2008 and August 2020 were selected for analysis. The research results are as follows. First, as a result of analyzing the general characteristics of research papers mediated directly by parents of children with autistic disorders, there were three group-designed studies (12.5\%) and fifteen single-subject studies (87.5\%). The study mainly conducted social interaction training, positive behavior support, complementary and alternative communication tools, central axis response training, sensory integration program, developmental play therapy, and a structured approach in relation to independent variables. Second, looking at the rating table for the qualitative indicators of evidence-based reality, it can be seen that 19 studies that satisfies the information on the subject of study were presented relatively faithfully compared to other items. Therefore, when conducting intervention studies on children with autism disorders, group design studies are also necessary, and evidence-based practical intervention strategies should be presented and implemented.
\end{abstract}

Keywords: Autism Spectrum Disorder, Disabled Parents, Research Trends, Evidence-based Practice

\section{Introduction}

\subsection{The Need for Research}

Autism Spectrum Disorder (ASD) is a neurodevelopmental disorder with neurobiological causes, characterized by persistent defects in social communication and social interaction limited and repetitive behavior interest or activity[1]. According to the 2019 Statistics Yearbook of Health and Welfare in the Republic of Korea, the number of persons with autism disorders continues to increase, with 11,874 persons in 2007, 16,906 persons in 2012, and 26,703 persons in 2018[2]. In addition, according to the 2020 special education statistics, out of the 95,420 persons subject to special education, 13,917 persons

Received: April 11, 2021; $1^{\text {st }}$ Review Result: May 28, 2021; $2^{\text {nd }}$ Review Result: July 19, 2021 Accepted: August 30, 2021 
with autism disorder special education are $14.6 \%[3]$, which is steadily increasing compared to $12.5 \%$ in 2016 .

Children with autism disorder have a lack of understanding of how to initiate and react to others for common interest, and because they have difficulty understanding the intentions of others expressed through language and gestures, they are unable to interact with others, including their family members. Experience difficulties[4].

It is estimated that the majority of children with autism disorder do not develop functional language[5], and many of these children do not understand oral language well. In particular, children with autism disorder show significant limitations in both the quantity and quality of verbal and non-verbal initiating behaviors compared to those who typically develop[6][7].

This is also supported by a report that the lack of social skills of children with autism disorder negatively affects not only early in their life but also various social relationships they face while growing up[8]. In addition, even if the child's communication ability improved as the child grew, or the acceptance of the child was relatively increased due to the decrease in parents' expectations, it was found that they were still experiencing stress from behavioral problems including aggression of the child[9].

Parents spend the most time with their children during the day to promote their children's development and meet their needs. Furthermore, parents play an important role in maximizing the educational effect of their children through team cooperation with related experts to provide services to their children[10] [11]. Children subject to special education have different types of disabilities and their degrees of disability, and are often not resolved through general developmental stages or educational theories[12], and it is difficult to acquire new skills naturally or independently[13]. In many cases, problematic behaviors appear seriously, leading to difficulties in parenting and education[14].

Recently, access to education for children with disabilities is not limited to only individual children, and awareness of support for children with disabilities and their parents is increasing[15][16]. As social consensus has been reached that the role of parents is very important in the development and education of children with disabilities[17], parental involvement in awareness and education of children with disabilities is becoming important. There is an emphasis on cooperation between parents and teachers. In addition to the active participation of parents in children with disabilities, research is being conducted with increasing interest in the stress and life of parents raising children with disabilities.

Parental participation is very important for early diagnosis and adequate support for children with autism disorders, and it is important to reflect on where each study began, where it is currently located, and where it is heading[18]. Therefore, at the present time when various studies on parents of children with autism disorder are being accumulated, understanding of what has been revealed in the studies related to parents of children with autism disorder to date and the topic and direction of the research that has been focused recently should be prioritized.

Evidence-based practice is a teaching technique that includes research method standards to bridge the gap between the experimental situation and the practice, and to ensure the improvement of students' performance level[19][20]. According to the U.S. Council for Exceptional Children's (CEC) special education evidence-based practice standard, for a research methodologically appropriate study, context and situation, participants, mediation providers, description of practice, mediation fidelity, internal validity, performance measurement/dependent variables, qualitative indicators such as data analysis should be met[21].

Research on evidence-based practice is being actively conducted in the field of special education in Korea[22-26]. The argument that research methods and the quality of research should be improved to meet CEC's evidence-based actual quality indicators is persuasive[20][27][28]. It is necessary to improve the standards and quality of research so that the application of interventions conducted by the parents of children with autism disorders is consistent with evidence-based practice, and to provide information so that the proven effective interventions are applied. 
In this study, the factors related to the parents of children with autism are specifically investigated in order to specify the methods and contents for support for parents of children with autism, and the experimental studies conducted by the parents of children with autism are a qualitative indicator of evidence-based practice. Based on this background, this study is aimed to review domestic papers between 2000 and 2020 about the parents of children with autism and examine effective parenting factors for children with autism. In addition, this study systematically categorizes researches on parents of children with autism, and studies the overall flow and pattern, providing a balanced development of research and a direction for future research, which can be helpful to children with autism. In addition, if the main characteristics of intervention studies conducted by parents of children with autism are revealed, research methods in this field can be improved, and it is expected that more effective intervention methods can be applied to the field of special education.

\subsection{Research Problem}

First, what are the general characteristics of domestic research on parents of children with autism disorders?

Second, what are the characteristics of the evidence-based actual qualitative indicators in domestic intervention studies involving parents of children with autism disorders?

\section{Research Method}

\subsection{Research Design}

This study completed research ethics education and received deliberation and approval (10414782020-HR-035) from the Nambu University Bioethics Committee according to the research ethics guidelines, and to analyze the research trends of parents with children with autism disorders in Korea. Korean journal articles published between 2008 and August 2020 were selected for analysis. This quailitative study was designed to analyze previous studied related to sutism in Korea, and the analysis conducted by a researcher and two PhDs in special education.

The literature selection criteria for this study are as follows.

First, the study subjects were limited to parents of children with autism disorders, and disability areas other than autism disorders were excluded from the area of disability. Second, all papers published in Korea and searchable through the search DB were included, and studies published before September 1, 2020, when the final search was conducted, were targeted. Third, the research method included all studies of parents of children with autism disorders, and included parents, fathers, and mothers. At this time, research on genes in the medical field was excluded. Fourth, the study design included all quantitative and qualitative studies on parents of children with autism disorders.

\subsection{Analysis Criteria}

This study selected 24 intervention studies conducted by parents of children with autism disorders, Independent variable, dependent variable, The study design was analyzed. In addition, characteristics based on qualitative indicators of evidence-based reality were analyzed. The qualitative indicator is prior studies that evaluated the qualitative level of group design research and single-object research in order to analyze thesis based on Twenty-eight detailed indicators in eight areas[20][28-30]. If the contents of the index were not satisfied, it was calculated as zero points, if only a part was satisfied, one point, and if completely satisfied, it was calculated as two points. 
[Table 1] General Feature Analysis

\begin{tabular}{cl}
\hline & \\
\hline Research subject & -Number of children participating \\
& -Number of participating parents \\
\hline & -Social interaction training \\
& -Support positive behavior \\
& -Complementary and alternative communication tools \\
Independent variable & -Center axis reaction training \\
& -Sensory integration program \\
& -Developmental play treatment \\
& -Structured Approach \\
\hline \multirow{3}{*}{ Dependent variable } & -Behavior change \\
& -Social interaction \\
& -Communication ability \\
& -Daily life function \\
& -Parent-related factors \\
& -Sensory control function \\
\hline \multirow{2}{*}{ Research design } & -Design method: group design study, single subject study \\
& -Reliability \\
& -Validity \\
& -Arbitration fidelity \\
\hline
\end{tabular}

\subsection{Reliability between Analysts}

This study analyzed the reliability between analysts for 24 papers that analyzed qualitative indicators based on evidence-based reality.

For the analysis of intervention studies based on evidence-based practice, a researcher and one person who has completed a doctoral course in special education department randomly selects 4 papers $(16.7 \%)$ to be analyzed, and is individually analyzed according to the general characteristics analysis items and the qualitative indicators of evidence-based practice After independently evaluating, consultation and training were carried out until the degree of agreement for each item reached $90 \%$. After the agreement between the analysts reached $90 \%$, the remaining 20 articles (approximately $83.3 \%$ ) were divided into 10 pieces by two analysts. The inter-analyst confidence in this study was $96 \%$.

\subsection{Data Processing}

The data processing method of this study is as follows.

First, in order to find out the general research trends of domestic research on parents of children with autism disorders, Independent Variable, Dependent Variable, The frequency and percentage for the study design were calculated.

Second, in order to find out the characteristics based on the evidence-based reality of intervention studies on parents of children with autism disorders, the qualitative index of CEC was applied and evaluated on a 3-point scale, and the frequency and percentage were calculated. When each variable was treated as overlapping, multiple responses were analyzed and marked.

\section{Results}

\subsection{General Characteristic Analysis}

For general characteristics, this study was analyzed by categorizing it into research subjects, independent variables, dependent variables, and research design. 


\subsubsection{Research Subject}

[Table 2] Analysis of the Research Subject

\begin{tabular}{|c|c|c|c|c|}
\hline Subject of study & Division & $\begin{array}{c}\text { Thesis } \\
\text { (Edition)/Number of } \\
\text { Persons (persons) }\end{array}$ & $(\%)$ & All $(\%)$ \\
\hline \multirow{5}{*}{ Number of children involved } & 1 person & 9 & 37.5 & \multirow{7}{*}{$\begin{array}{l}24 \text { episodes } \\
\quad(100 \%)\end{array}$} \\
\hline & 2 people & 2 & 8.33 & \\
\hline & 3 people & 9 & 37.5 & \\
\hline & 4 people & 1 & 4.17 & \\
\hline & 5 or more & 3 & 12.5 & \\
\hline \multirow{2}{*}{$\begin{array}{l}\text { Whether to indicate the gender of } \\
\text { the child }\end{array}$} & Notation & 21 & 87.5 & \\
\hline & Not marked & 3 & 12.5 & \\
\hline \multirow{3}{*}{ Child gender } & male & 34 & 55.74 & \multirow{3}{*}{$\begin{array}{c}61 \\
\text { occupants } \\
(100 \%)\end{array}$} \\
\hline & female & 14 & 22.95 & \\
\hline & Not marked & 13 & 21.31 & \\
\hline \multirow{3}{*}{ Number of parents involved } & part & 0 & 0 & \multirow{3}{*}{$\begin{array}{c}61 \\
\text { occupants } \\
(100 \%)\end{array}$} \\
\hline & mother & 36 & 59.02 & \\
\hline & parents & 25 & 40.98 & \\
\hline
\end{tabular}

As shown in [Table 2], the study subjects were 9 cases (37.5\%) with 1 child, 2 cases $(8.33 \%)$ with 2 participants, 9 cases (37.5\%) with 3 participants, and 1 case with 4 participants. (4.17\%), 3 cases $(12.5 \%)$ when more than 5 participants participated. When the gender of the child was indicated, 21 articles (87.5\%), when not indicated, 3 articles (12.5\%), and when the gender is indicated, 34 boys $(55.74 \%)$ and 14 girls (22.95\%). Was. Looking at the number of parents involved, there was no case that only the father participated, 36 cases $(59.02 \%)$ of mothers participated, and 25 cases $(40.98 \%)$ of parents participated together.

\subsubsection{Independent Variable}

[Table 3] Analysis of Independent Variables

\begin{tabular}{cccc}
\hline Independent variable & Number of thesis (edits) & $(\%)$ & All(\%) \\
\hline Social interaction training & 6 & 25.00 & \\
Support for positive behavior & 5 & 20.84 & \\
Environment-oriented mediation & 3 & 12.50 & 24 episodes \\
Complementary and alternative & 3 & 12.50 & $(100 \%)$ \\
communication tools & 2 & 8.33 & 8.33 \\
Central axis response training & 2 & 8.33 & \\
Sensory Integration Program & 2 & 4.17 & \\
Developmental play therapy & 1 & &
\end{tabular}

As shown in [Table 3], 6 pieces $(25.00 \%)$ for social interaction training, 5 pieces for positive behavior support $(20.84 \%), 3$ pieces for environment-centered interventions and complementary and alternative communication tools $(12.5 \%)$, and central axis response. Training, sensory integration program, and developmental play treatment were each two $(8.33 \%)$, and structured approach was one $(4.17 \%)$. Since the independent variable was a study conducted by parents, studies on social interaction training and positive behavior support were dominated. 


\subsubsection{Dependent Variable}

[Table 4] Analysis of Dependent Variable

\begin{tabular}{cccc}
\hline Dependent variable & Number of thesis (edits) & $(\%)$ & All(\%) \\
\hline Behavior change & 10 & 29.41 & \\
Social interaction & 9 & 26.47 & 17.65 \\
Communication skills & 6 & 11.76 & 34 types \\
Daily life function & 4 & 11.76 & $(100 \%)$ \\
Parent-related factors & 4 & 2.95 & \\
Sensory control function & 1 & \\
\hline
\end{tabular}

As shown in [Table 4], the dependent variables of the thesis analyzed for intervention studies were 10 types of behavioral change (29.41\%), 9 types of social interaction (26.47\%), 6 types of communication ability (17.65\%), daily life functions and parents. The related factors were 4 types $(11.76 \%)$ and 1 sensory control function $(2.95 \%)$. Therefore, it can be seen that more studies have been conducted on the child with autism disorder than on the parent factor as the dependent variable. In addition, as for the dependent variable, it can be seen that the study was designed mainly in accordance with behavior change, social interaction, communication ability, etc., which are themes to improve the main characteristics of children with autism disorder.

\subsubsection{Research Design}

[Table 5] Analysis of Research Design

\begin{tabular}{ccccc}
\hline Study design & Division & Number of thesis (edits) & $(\%)$ & All(\%) \\
\hline \multirow{2}{*}{ Design method } & Group Design Research & 3 & 12.5 & \\
& Single subject study & 21 & 87.5 & \\
Reliability & Mark & 22 & 91.67 & 24 episodes \\
& Not marked & 2 & 5.33 & $(100 \%)$ \\
Validity & Mark & 12 & 50.0 & 50.0 \\
Arbitration & Not marked & 12 & 58.33 & \\
fidelity & Mark & 14 & 41.67 & \\
\hline
\end{tabular}

As shown in [Table 5], the study design of the thesis for the analysis of interventional studies was 3 group-designed studies (12.5\%) and 21 single-subject studies $(87.5 \%)$. Among the papers to be analyzed, there were 22 studies $(91.67 \%)$ that indicated reliability and $2(8.33 \%)$ studies that did not. Among the papers to be analyzed, 12 studies $(50.0 \%)$ each with validity and no validity were the same. Among the papers to be analyzed, 14 studies (58.33\%) indicated the fidelity of intervention, and 10 studies $(41.67 \%)$ were not indicated.

\subsection{Analysis of Qualitative Indicators of Evidence-based Practice}

In accordance with CEC's (2014) criteria for evaluating the qualitative indicators of evidence-based practice, group design studies did not include the contents of 6.5, 6.6, 6.7, and 8.2 in the evaluation, and single-subject studies were 6.4, 6.8, 6.9, 7.6. , 8.1, and 8.3 are not included in the rating. As a result of analyzing the papers to be analyzed based on evidence-based actual qualitative indicators, the average 
of the environmental category was 1.04 points, the average of the research subject category was 1.69 points, the average of the mediator category was 1.36 points, and the average of the intervention fidelity category was 0.33 points. The average of the internal validity category was 0.78 points, the average of the dependent variable category was 1.27 points, and the average of the data analysis category was 1.39 points.

Eight areas of qualitative indicators of evidence-based reality in this study consist of environment, research subject, mediator, experiment, mediation fidelity, internal validity, dependent variable, and data analysis.

[Table 6] Qualitative Indicators of Evidence-based Practice

\begin{tabular}{|c|c|c|c|c|}
\hline \multirow[b]{2}{*}{ division } & & \multirow[b]{2}{*}{ Qualitative indicator } & \multicolumn{2}{|c|}{ Research method } \\
\hline & & & $\begin{array}{l}\text { Group } \\
\text { Design } \\
\text { Resear } \\
\text { ch }\end{array}$ & $\begin{array}{l}\text { Single } \\
\text { subject } \\
\text { study }\end{array}$ \\
\hline 1 & Environment & $\begin{array}{l}\text { (1) Describe the key features and key features of the context or environment. } \\
\text { E.g.) program or class type, school type, curriculum, geographic location, } \\
\text { community situation, society.Economic status, physical environment }\end{array}$ & 0 & 0 \\
\hline \multirow[b]{2}{*}{2} & \multirow[b]{2}{*}{$\begin{array}{l}\text { Subject of } \\
\text { study }\end{array}$} & $\begin{array}{l}\text { (2) Describe the demographic characteristics of the study participants (gender, } \\
\text { age/grade, religion/race, socioeconomic level, language level). }\end{array}$ & 0 & 0 \\
\hline & & $\begin{array}{l}\text { (3) How to determine the degree and degree of disability or risk (specific } \\
\text { learning disability, autism spectrum disorder, problem behavior) of the } \\
\text { research participant (IDEA standards, teacher recommendation, standardized } \\
\text { intelligence test, curriculum-centered evaluation, rating scale, etc.) Is } \\
\text { explaining. }\end{array}$ & O & ○ \\
\hline \multirow[t]{2}{*}{3} & \multirow[t]{2}{*}{ Moderator } & $\begin{array}{l}\text { (4) The role of research mediators (teachers, researchers, assistants, parents, } \\
\text { volunteers, peer mediators, siblings, engineering devices/computers), and } \\
\text { background variables (religion/race, educational background/qualification) } \\
\text { are explained. }\end{array}$ & 0 & 0 \\
\hline & & $\begin{array}{l}\text { (5) It describes the specific training (volume, training standards) or } \\
\text { qualifications (professional qualifications, etc.) required to apply the } \\
\text { intervention, indicating that the mediator has reached it. }\end{array}$ & 0 & 0 \\
\hline \multirow[t]{2}{*}{4} & \multirow[t]{2}{*}{ Experiment } & $\begin{array}{l}\text { (6) Intervention procedures (mediation components, instructional behavior, } \\
\text { major elements, manual or scripted procedures, amount of intervention) and } \\
\text { behavior of the mediator (facilitation, verbal expression, physical behavior, } \\
\text { access, etc.) in detail. I am explaining. }\end{array}$ & 0 & 0 \\
\hline & & (7) If tools (activity sheets, timers, clues, toys, etc.) are used, explain them. & O & ○ \\
\hline \multirow{3}{*}{5} & \multirow{3}{*}{$\begin{array}{l}\text { Arbitration } \\
\text { fidelity }\end{array}$} & $\begin{array}{l}\text { (8) Evaluate the fidelity of the intervention in relation to the severity of the } \\
\text { intervention using direct, reliable means (such as observation using a } \\
\text { checklist of the main elements of the experiment). }\end{array}$ & 0 & 0 \\
\hline & & $\begin{array}{l}\text { (9) Measure the integrity of the intervention for the amount of intervention } \\
\text { (exposure) using direct and reliable means (observation or self-report on the } \\
\text { duration, frequency, and scope of the curriculum). }\end{array}$ & 0 & 0 \\
\hline & & $\begin{array}{l}\text { (10) Assess and report on the fidelity of the arbitration throughout the } \\
\text { arbitration process. (a) The entire duration of the arbitration application period } \\
\text { (start-intermediate-end of the arbitration), (b) by moderator, environment, } \\
\text { participant, or other analysis unit }\end{array}$ & 0 & 0 \\
\hline \multirow{3}{*}{6} & \multirow{3}{*}{$\begin{array}{l}\text { Dot product } \\
\text { Validity }\end{array}$} & $\begin{array}{l}\text { (11) Researchers controlled and systematically manipulated independent } \\
\text { variables. }\end{array}$ & & \\
\hline & & $\begin{array}{l}\text { (12) Describes the conditions of the baseline (in a single subject study) or } \\
\text { control/experiment (in a group design study) such as curriculum, teaching, } \\
\text { and intervention (definition, duration, time, frequency, learner: professor's } \\
\text { ratio). . }\end{array}$ & 0 & 0 \\
\hline & & $\begin{array}{l}\text { (13) Subjects under control/experimental conditions or baseline conditions } \\
\text { have no or extremely limited access to interventions. }\end{array}$ & 0 & 0 \\
\hline
\end{tabular}


(14) Explain clearly how to assign participants to each group in one of the following ways. (a) random, (b) non-random, or comparison groups correspond similarly to the intervention group, (c) non-random, or statistical techniques are used to measure statistically significant differences (more than $5 \%$ standard deviation). . Example) Differences in pre-test scores or statistical characteristics of the two groups (such as ANCOVA), (d) Non-random (regression break model) according to appropriate cutoff points

(15) The study design shows the effect of at least three experiments at three different times.

(16) The baseline stage of the single-subject study design is at least three times or more.

\begin{tabular}{|c|c|c|c|c|}
\hline \multirow{4}{*}{6} & \multirow{4}{*}{$\begin{array}{l}\text { Dot product } \\
\text { Validity }\end{array}$} & $\begin{array}{l}\text { (16) The baseline stage of the single-subject study design is at least three } \\
\text { times or more. }\end{array}$ & & O \\
\hline & & $\begin{array}{l}\text { (17) Design control to secure internal validity (use of generally accepted } \\
\text { designs such as inverted design, mid- and multi-baseline design, etc.) }\end{array}$ & & ○ \\
\hline & & $\begin{array}{l}\text { (18) The overall decrease in study participants should be low within the group } \\
\text { (e.g. less than } 30 \% \text { over a year). }\end{array}$ & ○ & \\
\hline & & $\begin{array}{l}\text { (19) The difference in the reduction of study subjects between groups was } \\
\text { small (eg, } 10 \% \text { or less) or was controlled through adjustment. }\end{array}$ & O & \\
\hline \multirow{6}{*}{7} & \multirow{6}{*}{$\begin{array}{l}\text { Dependent } \\
\text { variable }\end{array}$} & $\begin{array}{l}\text { (20) Research results are socially important (quality of life, } \\
\text { developmental/learning outcomes, both theoretically and empirically } \\
\text { improved). }\end{array}$ & ○ & ○ \\
\hline & & $\begin{array}{l}\text { (21) The measurement of the dependent variable is clearly defined and } \\
\text { explained. }\end{array}$ & ○ & ○ \\
\hline & & (22) The intervention effect (not limited to the positive effect) is reported. & ○ & ○ \\
\hline & & (23) Results The frequency and timing of measurement are appropriate. & ○ & ○ \\
\hline & & $\begin{array}{l}\text { (24) Provide adequate evidence for internal reliability, inter-observer } \\
\text { reliability, and test-retest reliability. }\end{array}$ & O & ○ \\
\hline & & $\begin{array}{l}\text { (25) Providing adequate evidence (content, composition, criteria, social } \\
\text { validity, etc.) on validity. }\end{array}$ & O & \\
\hline \multirow{3}{*}{8} & \multirow{3}{*}{ Data analysis } & $\begin{array}{l}\text { (26) Data analysis techniques are suitable for comparing the performance } \\
\text { changes of two groups (or more) (t-test, ANOVA/MANOVA, } \\
\text { ANCOVA/MANCOVA, etc.). }\end{array}$ & ○ & \\
\hline & & (27) Provide a single target graph in which the results are clearly displayed. & & O \\
\hline & & $\begin{array}{l}\text { (28) Provide one or more statistics of an appropriate effect size, or provide an } \\
\text { appropriate effect size that can be calculated. }\end{array}$ & ○ & \\
\hline
\end{tabular}

\section{Discussion}

The discussion based on the results of this study is as follows.

First, as a result of examining the number of parents involved, there was no study involving only fathers, and $59.0 \%$ of studies involving only mothers. In addition, reliability was indicated in $91.6 \%$ of all studies, but the case where validity was not indicated occupied half of all studies. $41.6 \%$ of the studies did not indicate the integrity of the intervention. As indicators such as validity and arbitration fidelity are important indicators that affect the reliability of independent variables and the reliability of the research results as a whole[19][21], researchers need to manage them thoroughly.

Second, regarding the independent variable, social interaction training, positive behavior support, environment-centered intervention and complementary and alternative communication tools, central axis response training, sensory integration program, developmental play therapy, and a structured approach were implemented. Among the independent variables, social interaction training (25.0\%) accounted for the largest proportion, and positive behavior support was also studied (20.8\%). It seems necessary to study various independent variables such as complementary and alternative communication tools, sensory integration programs, and therapeutic approaches through more in-depth parental education. 
Third, it was found that the study was designed in accordance with the main characteristics of children with autism disorders, such as social interaction, behavior change, and communication ability, such as social interaction and communication ability. In order for the dependent variable to build an evidencebased reality, a clear operational definition of the dependent variable, validity and reliability of measurement should be verified[31]. Despite the fact that the dependent variable must be accurately measured, there have been many studies in which variable control was not performed accurately while living with parents.

Fourth, looking at the experimental design of the intervention studies, in the previous[28][32][33] that analyzes the evidence-based practice of single-objective studies in the field of special education. The experimental design for intervention for students with disabilities can be understood in a similar context to the report that there are many middle and multiple baseline designs. In the case of multiintermittent baseline design and multi-baseline design, it is easy to prove the experimental effect, but there is a risk factor that it is difficult to secure internal validity, so it seems that it is necessary to clearly understand and apply the evidence-based reality when designing a study.

Fifth, looking at the rating table for the qualitative indicators of evidence-based reality, in the case of information on the research environment, $29.1 \%$ and $58.3 \%$ information on the selection criteria for research subjects, it seems necessary to design more clearly about the research environment or screening criteria. The items on the evaluation of the fidelity of the arbitration related to the strictness of the intervention and the measurement of the fidelity of the intervention to the amount of intervention are $91.6 \%$ and $100 \%$, respectively. Even in controlling the risk factors of internal validity, $80.3 \%$ of the cases were not satisfied. This is a case where education or training is performed while living with parents, and it is considered that a more detailed design is necessary in a future study. As for the dependent variable, most of the studies satisfies the qualitative index in many cases, and $76.1 \%$ of the studies provide a single target graph, so it is necessary to refer to the results of future studies.

\section{Conclusions}

Based on the discussion of this study, conclusions are presented as follows.

First, there were a total 24 intervention studies targeting parents of children with autism disorders

Second, regarding the independent variable, social interaction training, positive behavior support, environment-centered intervention and complementary and alternative communication tools, central axis response training, sensory integration program, developmental play therapy, and a structured approach were implemented

Third, it was found that more studies were conducted on children with autism disorders than on parental factors as the dependent variable.

Fourth, when looking at the experimental design of the intervention study, the most frequent intermediate and intermittent baseline designs were followed by the middle and multiple baseline designs.

Fifth, it can be seen that the education table for the qualitative indicators of evidence-based reality satisfield the research information in most studies and was presented relatively faithfully compared to other items.

In this study, through the analysis of domestic intervention studies, we researchers analyzed whether there is an intervention with scientific evidence that meets the actual evidence-based criteria, and there seems to be no intervention that meets all the criteria yet. However, in the study, only previous studies related to parents of children with autism were analyzed, and the study period was also limited, so there are limitation in generalization. Therefore, in future studies, a study that presents the characteristics of children as an average through a group study for children with autistic disorders is also necessary.

The implications of this study, such as support for parents of children with autism, can be seen in that 
this study tried to clarify evidence-based reality based on the domestic research on parents of children with autism. Evidence-based practice means having a scientific basis to prove the performance of an educational program or teaching method actually used. Therefore, in this study, we analyzed whether there are any interventions with scientific evidence that conform to the evidence-based actual standards through the analysis of domestic intervention studies. The results shown in this study have several implications as follows when conducting a study on the parents of children with autism in the future. First, selecting and using a method with proven results is an important task to increase the effectiveness of interventions for children with autism. Therefore, when conducting interventional research on children with autism, it is thought that evidence-based intervention strategies should be presented and implemented. In addition, it seems that continuous attention should be paid to the development and effectiveness of new intervention strategies according to the unique characteristics of the domestic field as in [34].

\section{Acknowledgments}

This study was supported(in part) by research funds from Nambu University, 2021. This work was supported by the Ministry of Education of the Republic of Korea and the National Research Foundation of Korea (NRF-2020S1A5A2A03044034).

\section{References}

[1] American Psychiatric Association, Diagnostic and statistical manual of mental disorders (5th ed.), Arlington, VA: American Psychiatric Publishing, (2013)

[2] Ministry of Health and Welfare, Health and Welfare Statistical Yearbook 2019, (2019), Vol.65

[3] Ministry of Education, Special Education Statistics 2020, Korea: National Institute of Special Education, (2020)

[4] I. P. Oono, E. J. Honey, H. McConachie, Parent-mediated early intervention for young children with autism spectrum disorders(ASD), British Journal of Psychiatric Advances, (2016), Vol.22, No.3, pp.146-146.

[5] C. Lord, M. Rutter, Autism and pervasive developmental disorders, Child and Adolescent Psychiatry: Modern Approaches, UK Oxford: Blackwell, (1994)

[6] B. Newman, Self-management of Initiations by Students Diagnosed with Autism, The Analysis of Verbal Behavior, (2005), Vol.21, No.1, pp.117-122, doi: 10.1007/BF03393013

[7] P. Warreyn, H. Roeyers, U. Van Wetswinkel, I. De Groote, Temporal coordination of joint attention behavior in preschoolers with autism spectrum disorder, Journal of Autism and Developmental Disorders, (2007), Vol.37, No.3, pp.501-512.

[8] H. S. Park, Family support plan for families of children with autistic disorders, Special Education, (2006), Vol.5, No.2, pp.5-30.

[9] D. E. Gray, Everybody just freezes, Everybody is just embarrassed: felt and enacted stigma among parents of children with high functioning autism, Sociology of Health \& Illness, (2002), Vol.24, No.6, pp.734-749, DOI: 10.1111/14679566.00316

[10] E. J. Park, B. I. Lee, A Qualitative Study on Perception \& Needs of Early Childhood Special Education Teachers on Family Support, Special Education Disputes, (2017), Vol.32, No.2, pp.1-29.

[11] W. H. Won, S. C. Kwak, Analysis of the Trend and Tasks in Qualitative Research about Families of Children with Disabilities, Special Educational Studies, (2015), Vol.50, No.1, pp.27-47.

[12] H. Y. Kim, Suggestions on Family Support Program for Children with Visual Impairments Based on the Content Analysis of Counselling Cases, Journal of Visual Impairment, (2009), Vol.25, No.1, pp.27-47. 
[13] N. Ozcans, A. Cavkaytar, Parents as teachers: Teaching parents how to teach toilet skills to their children with autism and mental retardation, Education and Training in Autism and Developmental Disabilities, (2009), Vol.44, No.2, pp.237-243.

[14] L. H. William, Trend Special Education, 10ed., Korea: Sigmapress, (2013)

[15] M. S. Lee, K. J. Kim, A Study on the Family Support Plan for Infants with Disabilities, Korea: National Institute of Special Education, (2000)

[16] B. I. Lee, H. G. Jo, A Study on Contents and Application of Family Support Programs Based on the Family Needs of Younger Children with Developmental Delays, The Journal of Special Education: Theory and Practice, (2000), Vol.11, No.2, pp.215-250.

[17] National Academy of Sciences-National Research Council, Washington DC, Educating children with autism, USA: ERIC Clearinghouse, (2001)

[18] E. Y. Chae , M. J. Cheong, An Meta-analytic Review of a Group Play Therapy Programme in Korea, Korean Journal of Play Therapy, (2016), Vol.19, No.2, pp.159-177.

[19] B. G. Cook, S. C. Cook, Unraveling evidence-based practices in special education, Journal of Special Education, (2013), Vol.47, No.2, pp.71-82.

[20] J. H. Kim, H. O. Park, A Analysis of Experimental Research on the Students with Intellectual Disabilities Based on the Quality Indicators of Evidence-Based Practices, The Journal of Special Education: Theory and Practice, (2018), Vol.19, No.4, pp.157-176.

[21] S. D. Hong, K. J. Jung, Are Direct Instruction Math Programs in Korea Evidence-Based Practices, Seoul National University of Education, The Journal of Korea Elementary Education, (2015), Vol. 26, No.1, pp.363-377.

[22] K. Y. Kim, W. H. Lee, S. C. Kwak, J. A. Noh, A Literature Review on Single Subject Research about the Improvement of Social Skills in Students with Autism Spectrum Disorder, The Journal of Special Education: Theory and Practice, (2014), Vol.15, No.3, pp.137-160.

[23] Y. J. Seo, K. E. Na, Evaluating Evidence-Based Interventions in Subject Areas for Students with Intellectual Disabilities, The Journal of Special Children Education, (2012), Vol.14, No.1, pp.435-466.

[24] H. J. Seo, H. J. Lim, literature review on effects of student-directed learning strategies to improve education outcomes of students with learning disabilities, The Journal of Special Education: Theory and Practice, (2015), Vol.14, No.4, pp.287-314.

[25] E. Zii, Y. J. Ahn, Systematic Review on Academic Interventions for Children with Autism Spectrum Disorders: Use of Evidence-Based Quality Indicators for Single Subject Design Studies, Specail Education, (2016), Vol.15, No.3, pp.227-250.

[26] S. M. Cho, J. M. Oh, Meta-analysis and analysing quality indicators of intervention on problem behaviors for elementary students with autism spectrum disorders, Journal of Behavior Analysis and Support, (2016), Vol.3, No.1, pp.1-24.

[27] J. Y. Kim, Trend and Issues in Research Related to the Young Children with disabilities in Korea, Journal of Special Education \& Rehabilitation Science, (2018), Vol.57, No.1, pp.153-171.

[28] G. S. Seong, M. A. Park, Analysis of the Single Subject Design Studies on Integration of Elementary School Students with Disabilities based on the Quality Indicators of Evidence-Based Practice, The Journal of Special Education: Theory and Practice, (2017), Vol.18, No.2, pp.171-198.

[29] S. Y. Moon, J. H. Hong, Y. R. Kim, A Systematic Review on Peer Relation Intervention for Children with Autism Spectrum Disorders, Jounal of the Korean Association for Persons with Autism, (2016), Vol.16, No.83, pp.83-109.

[30] A. K. Jitendra, C. Burgess, M. Gajria, Cognitive strategy instruction for improving expository text comprehension of students with learning disabilities: The quality of evidence, Exceptional Children, (2011), Vol.77, No.2, pp.135-159.

[31] R. H. Horner, E. G. Carr, J. Halle, G. McGee, S. Odom, M. Wolery, The use of single-subject research to identify evidence-based practice in special education, Exceptional Children, (2005), Vol.71, pp.165-179. 
[32] J. H. Kim, J. K. Cha, A Review of Experimental Research on Children with Developmental Delays: Focusing on Single-Subject Research, Journal of Emotional \& Behavioral Disorders, (2016), Vol.32, No.2, pp.267-288.

[33] H. J. Nam, E. J. Shim, K. I. Han, Y. R. Kim, Analysis of Single Case Studies` Trends of Intervention Studies in Mathematics and Study Rigor through the Quality Indicators, The Journal of Special Education: Theory and Practice, (2015), Vol.16, No.4, pp.409-432.

[34] S. H. Lee, E. J. Ahn, Evidence-based Practical Exploration for Students with Autism Spectrum Disorder: Focusing on Qualitative Indicator Analysis of Korean Studies, Autism Disorder Research, (2017), Vol.17, No.3, pp.1-28. 